Article

\title{
The Impact of Coercive Pressures on Sustainability Practices of Small Businesses in South Africa
}

\author{
Reginald Masocha * (i) and Olawale Fatoki \\ School of Economics and Management, University of Limpopo, Sovenga 0727, South Africa; \\ olawale.fatoki@ul.ac.za \\ * Correspondence: reemasocha@gmail.com or reginald.masocha@ul.ac.za; Tel.: +27-15-268-2802
}

Received: 20 June 2018; Accepted: 9 August 2018; Published: 27 August 2018

\begin{abstract}
The study sought to examine the role that coercive isomorphic pressures play in the sustainable development practices by small and medium enterprises (SMEs). The survey research approach was utilised in the research through 222 self-administered questionnaires distributed to SME owners and managers. The structural equation modelling (SEM) method was utilised to analyse the data through the Maximum Likelihood Estimation (MLE) method in Amos Version 24 software. Major findings in this study are that coercive isomorphic pressures have a significant impact on all the three dimensions of sustainable development which are economic, environmental and social. The implications are that government, environmental pressure groups and other stakeholders need to take into consideration the coercive pressures such as laws and regulations in pressuring small businesses to enhance sustainability practices. The research contributes by unearthing the extent to which coercive pressures impact the behaviour and practices of SMEs in sustainability practices. The study indicates that eventually small firms are expected to behave the same when it comes to adopting sustainability practices due to coercive isomorphism. The findings of this study further contribute toward understanding the concept of sustainable development in practice and theory.
\end{abstract}

Keywords: coercive isomorphism; sustainable development; structural equation modelling; SMEs; South Africa

\section{Introduction}

Sustainable development is a contemporary phenomenon challenging all firms, including small and medium enterprises (SMEs) [1]. Sustainable development is a concept constituting three dimensions, namely, economic, societal and environmental and is attributed to the Brundtland's Commission report titled "Our Common Future" [2]. Sustainable development cuts across academic, social and political backgrounds [3]; as such, it has been met with diverse views and perspectives [4,5]. For the business world, Swanson and Zhang [4] argue that businesses depend on sustainable development and sustainable development depends on businesses. However, implementing sustainable development, a relatively new concept is still a battle for businesses [6].

Consequently, how businesses are implementing sustainable development needs to be examined, given the vitality and infancy of the concept. SMEs and large firms, alike, are increasingly regarded as essential to sustainable development, although SMEs' activities are reckoned to be of little effect [7]. SMEs have been esteemed as engines of economic growth [8-10] poverty alleviation [9], rural development, innovation and technological developments, as well as, employment creation [11]. As such, their role towards sustainable development should be of high significance and worthwhile of research. Several academics have indicated that SMEs have challenges in comprehending sustainability issues [12-14]. However, this does not relieve SMEs of their sustainability duties and responsibilities. 
Theoretically, studies that consider sustainable development from the SMEs' perspective are scarce. As literature posits, much of sustainability academic work is largely biased towards large corporations and is primarily located in developed nations [15]. Thus, despite the critical economic role played by SMEs in many economies, especially the emerging economies, there is lack of empirical studies that address the sustainability concept, holistically in the SMEs context [12]. Subsequently, with numerous and significant differences between SMEs and large corporations, there are research and literature gaps that this study endeavours to answer. Foremost, many of the sustainable development mechanisms and tools were developed with large corporations in mind and are difficult if not impossible for SMEs to adopt $[13,14]$. Hence, this research seeks to attest findings from research on large corporations and in developed nations that have examined the relationship between coercive isomorphism and sustainable development practices [16,17].

Thus, as pressures for businesses to implement sustainable practices increase, this study endeavours to attest the role of coercive isomorphic pressures towards sustainable development practices amongst SMEs. When faced with a new environmental setting, the phenomenon of coercive isomorphism has been attributed with contributing towards adaptation in firm behaviour. Accordingly, coercive isomorphism has been used to explain the diffusion of various new business environmental trends such as technological adoption and total quality management within industries [18]. Isomorphism is a constraining process that pressures organisations to resemble other organisations under the same environmental conditions [19]. Empirical studies on isomorphism have focused on one aspect of isomorphism which is mimetic isomorphism and environmental sustainability within the sustainability discourse. The link between coercive isomorphism and sustainability practices on SMEs has not been explored in South Africa [20]. Thus, the aim of this study was to understand the influence of coercive isomorphism on sustainable development practices of small businesses in Limpopo Province. The question underpinning this study is: "how are sustainable development practices by SMEs influenced by coercive isomorphic pressures?"

Unlike in developed countries were efforts to investigate the effect of coercive isomorphic pressures on sustainability practices is largely found, the South African milieus are somewhat liberal and evasive. Research from other countries has shown that regulations in the area of sustainable development are more clear and operative [16,17]. Although policies have been promulgated within the South African environmental sustainability context, their implementation, enforcement and monitoring barely exist. As such, the larger proportion of coercive forces that would operationalise sustainability are non-regulatory such as customers, suppliers, intermediaries and other counterparts' demands [21]. Therefore, this paper contributes further insights to ongoing research on the relationship between coercive isomorphism and sustainable development practices by considering the developing world context. The paper constitutes six sections, namely, a literature review on SMEs, coercive isomorphism and sustainable development concepts, as well as the methodology, results, discussion and conclusions of the study.

\section{Literature Review}

\subsection{SMES}

A single definition of SMEs seldom exists in literature [11,22]. Maduku et al. [11] highlight that the definition of an SME is a continuously contentious element in the literature. It is deemed that the definition of SMEs varies as one moves from one industry to the other, and more so, across countries. In this regard, it is a prominent practice for studies that deal with SMEs to first provide a background and definition of SMEs. The absence of a commonly accepted definition for SMEs seems to emanate from the fact that the classification of businesses into large, medium or small scale is a subjective and a qualitative judgement matter [23]. Regardless of the various definitions of SMEs that may exist, the primary focus is on either the number of employees or the amount of invested capital [24]. 
For the purposes of this study, an SME is defined as a firm which is independently owned, employing less than 200 full-time employees, with total annual turnover of less than R40 million and with a total gross fixed assets value (fixed property excluded) of less than R15 million. This definition disregards the differences that apply in terms of the differences in industry as outlined in the definition with regards to the National Small Business Act No 102 of South Africa 1996 as amended in 2003. Thus, the research is concerned with the behaviour of SMEs in general disregarding the specificities in terms of industry differences.

Attention towards SMEs' general contribution towards the economy has been growing in literature. Considering the position that SMEs occupy in the global as well as the South African sphere, their role towards sustainable development cannot be understated. SMEs have been a prime research subject for some time in South Africa, commanding interest from both the private and public sectors due to their strategic role in driving economic growth and wealth creation, primarily in historically disadvantaged populations [11]. SMEs are regarded as the backbone of most African countries [25]. However, the dilemma in the absence of a single and universally accepted definition of what constitutes an SME is still prevalent in Africa.

\subsection{Coercive Isomorphism}

The institutional organisational theory, as postulated by Di Maggio and Powell [26], is popularised in literature as the background for institutional isomorphism. The theory of institutional isomorphism has been widely utilised in research to understand similarities ranging from the outlook of educational textbooks to understanding the similarities in non-profit and profit making organisations [27]. The institutional theory espouses that organisations of all classes modify configurations consistent with the presence and setup of organisations in their proximity and location [28]. Under institutional isomorphism [29], a firm primarily experiences coercive pressures wielded by other firms which it is subjective to for its continual existence [30,31]. Coercive isomorphism emanates from compelling pressures that are either formal or informal [28]. Informal pressures can originate from the cultural forces and expectations of a community or environment in which the organisation exists in. Coercive pressures may also emanate from the formal government laws and regulations pertaining to issues like pollution controls, taxation and accounting rules. Furthermore, coercive pressures entail expressed regulative practices such as rules, assessments and codes of practices [31]. These emanate from regulatory institutions and prevailing legislature which prescribe firms' practices pertaining to the business environment. Key stakeholders such as customers, non-governmental organisations (NGOs) and other interest groups contribute towards coercive isomorphism [30].

For some time, the dimension of coercive mechanism of isomorphism has received much research attention [32]. Coercive isomorphic pressures happen because organisations are deemed to rely on their external environments for resources that enhance survival. Thus, successful organisations are those which can negotiate with external pressures for resources. Consequently, coercive isomorphism is as a result of pressures emanating from external sources of resources that organisations depend on. Amongst others, these external sources of resources which exert pressure on firms to conform to the expected sociocultural aspect of the broader society include the state and credit providers as important factors [33]. Thus, coercive isomorphism legitimacy is enforced legally. With coercive isomorphism, coercive pressures may be perceived by organisations as a force, persuasion or invitation to enter collusion [34]. On the other hand, there are institutional seductions and inducements that transpire in coercive isomorphism [35]. In this instance, firms may not be pushed towards adopting certain structures; instead there is a significant incentive to do so. The incentives are often related to monetary resources, whereby governments provide grant funding and various monetary opportunities, subject to the adoption of certain structures and practices. However, institutional theorists opine that coercive mechanisms seldom lead to efficiency [30]. 


\subsection{Sustainable Development}

The sustainable development hype is related and often interchangeably used with concepts such as corporate social responsibility (CSR) and sustainability management, and these concepts continue to attract attention in management literature and corporate practices $[14,36]$. The World Commission on Environment and Development (WCED) report relates that sustainable development requires firms to simultaneously develop long-term economic, social and environmental principles [37]. Thus, for firms to express sustainable development, they should utilise these principles (economic prosperity, societal wellbeing and environmental promotion) in their products, policies and practices. Scepticism is found in various circles that held that environmental integrity and social equity contradict economic prosperity [37]. The following discussion provides an analysis of the three dimensions of sustainable development and how hypotheses are structured in this study.

\subsubsection{Economic Sustainability}

The concept of economic sustainability pertains to minimisation of operating costs utilising systematic management, improved productivity of the labour-force, enhanced expenditures on research and development as well as investments in training and other human capital kinds [38]. The economic dimension is focused on the distribution of resources that are scarce [39]. Accordingly, economic sustainability pertains to turnover growth or stability, payment of taxes to government, payroll enhancements, as well as, growth in profitability, investments, and exports [40]. Furthermore, the economic dimension includes reduction of operating costs through systematic management, labour productivity, expenditures on research and development and investments in training and other forms of human capital [38]. Nowadays, long-term sustainable competitive advantage through new products or ideas, quality, costs or time is difficult to maintain. This is due to endless competitive cycles caused by reactive strategies i.e., me-too products and differentiation strategies amongst rivalry firms which eventually are destructive [1,41]. In this regard, a study by Iederan et al. [10] discovered that SMEs tend to adopt a non-isomorphic behaviour as a way of responding to changes in competitive environments. Research found that isomorphic pressures play a critical role in economic sustainability for SMEs $[13,33]$. On the background of the above discussion, this study put forward the following hypothesis:

Hypothetical 1 (H1). There is a significant positive relationship between perceived coercive pressures and economic sustainability practices of SMEs in South Africa.

\subsubsection{Environmental Sustainability}

Environmental sustainability refers to the maintenance of natural capital by regulating the impact of human activities (human footprints) on the natural environment. It involves responsible use of renewable and non-renewable resources, regulated pollution and waste assimilation [8]. The dimension of environmental sustainability is prominently described by the principle of environmental integrity which requires that people's actions need not destroy the earth's land, air and water resources. Recent research established that institutional isomorphism is prevalent in the context of environmental sustainability [42]. However, variables of sustainability implementation, performance, monitoring and evaluation have not yet been satisfactorily examined in literature [6]. Zhu and Sarkis [43] established that firms are influenced by coercive isomorphic pressures, especially manufacturers being the top polluters and responsible for much of the depletion of resources more than their counterpart firms, as such, they are subjected to more external pressure. A study in Malaysia by Hsu, Tan, Zailani and Jayaraman [44] also established that manufacturers were driven by coercive pressures to practise environmental sustainability in their operational processes. In their study, they established that competitor pressure and regulatory pressures were the most influential ones. On the other hand, the significance of isomorphic pressures pertaining to the implementation of sustainable practices is getting increasingly paramount [45]. By so doing, it is imperative to research isomorphism in 
environmental sustainability as a most likely phenomenon [19]. In this regard, the following hypothesis was formulated to address this gap in this study:

Hypothetical 2 (H2). There is a significant positive relationship between perceived coercive pressures and environmental sustainability practices of SMEs in South Africa.

\subsubsection{Social Sustainability}

Social sustainability primarily focuses on society and social development [46]. Firms as critical institutions in society are regarded as instruments of social justice [39]. Thus, firms are expected to embrace legal, ethical, and social-economics of all stakeholders and not only financial stakeholders. Social sustainability entails that firms should be responsible in their dealings with consumers, investors, government and employees [47]. Furthermore, the branch of social sustainability requires firms to manage their internal affairs by ensuring employee motivation through mechanisms that result in value for the firm [47]. Coercive isomorphism and social sustainability practices have not been directly researched amongst SMEs. Studies in other areas, such as Joseph and Taplin [48] have established a significant positive relationship between social sustainability and mimicry isomorphism amongst municipalities in Malaysia. While, social sustainability was found to be significantly related to coercive isomorphism due to trade unions, in particular [49]. Research by González [33] failed to establish a positive relationship between isomorphism and social sustainable practices of firms within the Spanish electrical industries. This study therefore sought to advance the emerging field of sustainable development by addressing how coercive isomorphic pressures influence social sustainability amongst SMEs in a developing country. In this regard, the following hypothesis was postulated to investigate the relationship between social sustainability and coercive isomorphism in this study:

Hypothetical 3 (H3). There is a significant positive relationship between perceived coercive pressures and social sustainability practices of SMEs in South Africa.

\section{Research Methodology}

The study area for this study is the Capricorn District Municipality (CDM) which is located in the Limpopo Province. Epistemologically, this study is of a positivism nature and utilised the objectivism ontological position. Methodologically, the quantitative research approach was used. The positivism research paradigm stresses the value of utilising or copying methods that are used in natural sciences [50] and is steered by theory and holds that reality is objectively provided and is capable of providing guidelines for how firms, workers and customers should behave. The survey technique was utilised in this study using a personally distributed self-administered questionnaire. The data gathering process transpired during the months of August and September 2017.

Convenience sampling was applied as a method of gathering data for the study. Convenience sampling was employed because obtaining a population for the purposes of probability sampling was practically impossible as most SMEs in the area operate informally. The sample constituted SMEs from various industry sectors and the study focused on the aggregate behavior of SMEs, regardless of the industry sector. The research instrument used in this study was formulated following an extensive literature review process (See Appendix A) and the questionnaire was primarily comprised of 5-point Likert scale type of questions. To measure sustainable development, a former scale developed by Høgevold et al. [6] was adopted in this study. The Cronbach alpha test for reliability for each factor in this scale ranged between 0.66 and 0.68 , which is greater than the recommended threshold of 0.6 . To measure coercive isomorphism, the scale developed by Lin and Sheu [19] was adopted for this study. The scale had a Cronbach alpha test of reliability which exceeded 0.7 and was deemed satisfactory. Thus, the adopted scales satisfied the requirements in terms of psychometric properties.

Data analysis was accomplished using Statistical Package for Social Sciences (SPSS) Version 24. To attain conclusions to the hypotheses, the premises of Structural Equation Modelling (SEM) were 
utilised. SEM, a multivariate analytical technique is an alternate to the conventional multiple regression analysis [51] and is advantageous in its ability to concurrently test a set of dependence associations between endogenous and exogenous variables. SEM followed the prominent two-staged approach, namely, measurement model and structural model. The measurement model constituted two aspects, namely, confirmatory factor analysis and the assessment of reliability and validity [52]. The latent constructs were assessed for fitness and how the observable variables loaded towards their respective constructs. The assessment was rigorously conducted utilising the software Analysis of a Moment Structure (AMOS) version 24. Amos software has been regarded as an easy-to-use package within the structural equation modelling spectrum [53]. In SEM, manifest or observed variables also called indicators represent the questionnaire items using rectangles or squares [54]. The latent variables or constructs, which are also called unobserved variables, represent the hypothesised relationships and appear as circles or ellipses. Through the use of CFA, this study was able to determine a comprehensive parsimonious aspect within the study [55].

Whilst the measurement model pertains to the relationships between latent variables and their respective observed variables, the structural model is concerned with the relationships between the latent variables [56]. Following the validation and attainment of satisfactory fitness on all the constructs in the measurement model, the structural model can be assessed as the second and last stage of SEM. Thus, in this case, the causal relationships between coercive isomorphism and sustainable development (economic, environmental and social) are assessed. Alternatively, the causal relationships that were stipulated in the hypotheses are evaluated in the structural model.

\section{Results and Discussion}

SEM needs a sample size of 200 or more respondents to be operative. Table 1 below shows information on the respondents.

Table 1. Sample characteristics.

\begin{tabular}{llcc}
\hline \multicolumn{1}{c}{ Variables } & \multicolumn{1}{c}{ Category } & Frequency & Frequency (\%) \\
\hline \multirow{2}{*}{ Gender } & Male & 104 & 46.8 \\
& Female & 118 & 53.2 \\
\hline \multirow{3}{*}{ Age } & 20-30 years & 77 & 34.7 \\
& 31-40 years & 88 & 39.6 \\
& 41-50 years & 46 & 20.7 \\
& Above 50 years & 11 & 5.0 \\
\hline \multirow{2}{*}{ Position in business } & Owner & 123 & 55.4 \\
& Manager & 99 & 44.6 \\
\hline \multirow{3}{*}{ Number of employees } & 5 and Below & 79 & 35.6 \\
& 6-20 & 96 & 43.2 \\
& 21-50 & 39 & 17.6 \\
\hline \multirow{2}{*}{ Location of business } & 51-200 & 8 & 3.6 \\
\hline \multirow{2}{*}{} & Rural & 45 & 20.3 \\
\hline
\end{tabular}

\subsection{Measurement Model}

In this study, the reliability of the constructs was determined through Cronbach's alpha and construct reliability (CR) coefficients. Initial exploratory factor analysis (EFA) showed that the factor loadings were all significantly positive and exceeded the cut-off level of 0.50 . As such, there were no significant cross-loadings, thus, leading to the retention of all the items for further analysis, no items were dropped for high loadings on more than one factor. The Cronbach's alpha test resulted in significant reliability coefficients that were all above 0.90 signifying high scale reliability. Construct reliability (CR) which is also called composite reliability was computed utilising information on 
factor loadings as well as error variances. As shown in Table 2, the Cronbach alpha coefficients for all the constructs reviewed high internal consistency as shown by the values that exceeded the recommended 0.7. Also shown in Table 2 below, all the $C R$ values are highly above the recommended 0.8 thereby indicating high levels of reliability of the scale utilised. Furthermore, the standardised factor loadings (SFLs) and average variance extracted (AVE) were used to assess convergent validity whilst discriminant validity was ascertained through inter-construct correlation coefficients and square root of AVE, compared. The results show satisfactory convergent validity through AVE and factor loading values which were above 0.50 . Table 3 depicts satisfactory discriminant validity as shown by square root of AVE that were higher than the inter-construct correlation coefficients.

Table 2. Confirmatory Factor Analysis results.

\begin{tabular}{|c|c|c|c|c|c|c|}
\hline Factor & Item & SFLs & Cronbach's $\alpha$ & AVE & CR & R-Squared \\
\hline \multirow{4}{*}{ Coercive } & Coe1 & 0.959 & 0.964 & 0.682 & 0.965 & - \\
\hline & Coe2 & 0.943 & & & & \\
\hline & Coe3 & 0.937 & & & & \\
\hline & Coe4 & 0.898 & & & & \\
\hline \multirow{6}{*}{ Economic } & Eco1 & 0.683 & 0.912 & 0.622 & 0.907 & 0.37 \\
\hline & Eco2 & 0.804 & & & & \\
\hline & Eco3 & 0.877 & & & & \\
\hline & Eco4 & 0.936 & & & & \\
\hline & Eco5 & 0.763 & & & & \\
\hline & Eco6 & 0.627 & & & & \\
\hline \multirow{7}{*}{ Environmental } & Env1 & 0.867 & 0.946 & 0.873 & 0.937 & 0.57 \\
\hline & Env2 & 0.890 & & & & \\
\hline & Env3 & 0.869 & & & & \\
\hline & Env5 & 0.854 & & & & \\
\hline & Env6 & 0.808 & & & & \\
\hline & Env7 & 0.735 & & & & \\
\hline & Env8 & 0.744 & & & & \\
\hline \multirow{7}{*}{ Social } & Soc1 & 0.758 & 0.903 & 0.573 & 0.903 & 0.39 \\
\hline & Soc2 & 0.842 & & & & \\
\hline & Soc3 & 0.837 & & & & \\
\hline & Soc4 & 0.645 & & & & \\
\hline & Soc5 & 0.839 & & & & \\
\hline & Soc6 & 0.723 & & & & \\
\hline & Soc7 & 0.618 & & & & \\
\hline
\end{tabular}

CR, construct reliability; AVE, average variance extracted.

Table 3. Descriptive statistics, correlations, square root of average variance extracted (AVE).

\begin{tabular}{lcccccc}
\hline \multicolumn{1}{c}{ Factor/Item } & Mean & SD & $\mathbf{1}$ & $\mathbf{2}$ & $\mathbf{3}$ & $\mathbf{4}$ \\
\hline 1 Coercive Isomorphism & 3.045 & 0.128 & $\mathbf{0 . 9 3 4}$ & & & \\
2 Economic Sustainability & 3.825 & 0.042 & 0.61 & $\mathbf{0 . 7 8 9}$ & & \\
3 Environmental & 2.929 & 0.149 & 0.71 & 0.62 & $\mathbf{0 . 8 2 6}$ & \\
sustainability & 3.787 & 0.078 & 0.55 & 0.56 & 0.58 & $\mathbf{0 . 7 5 7}$ \\
4 Social sustainability &
\end{tabular}

$\mathrm{SD}$, standard deviation. The square root of AVE (Average Variance Extracted) values are presented diagonally (in bold). Scores: 1 - strongly disagree; 2 -disagree; 3 -neutral; 4 -agree; 5 - strongly agree.

Furthermore, CFA was conducted using AMOS version 24 software and resulted in significant factor loadings on all the indicators. The constructs correlation coefficients were within the expected parameters of less than 0.8 for the purposes of multicollinearity ranging between 0.55 and 0.71 . The model fitness indices showed a need for re-specification. The analysis of standardised residuals showed that one indicator (Env4) under environmental sustainability had residuals of 3.016 and 
2.666 which were above the recommended threshold of within $+/-2.58$ values [57]. As such, it was deleted as it potentially caused fitness problems. The subsequent model resulted in a significant chi-square (chi-square $=63.118, \mathrm{df}=24, p=0.000, \mathrm{~N}=222$ ) signifying a poor model fit. As noted, the chi-square is most likely never going to be insignificant on large sample sizes of above 200 . However, considering other goodness-of-fit indices, namely, GFI $=0.948, \mathrm{NFI}=0.960, \mathrm{CFI}=0.974$, $\mathrm{TLI}=0.960, \mathrm{RFI}=0.940, \mathrm{AGFI}=0.902, \mathrm{RMR}=0.047, \mathrm{RMSEA}=0.086, \mathrm{SRMR}=0.0448$, and the Chi-square $/ \mathrm{df}=2.630$ the model presented significant good fitness.

\subsection{Structural Equation Modelling}

The R-squared values $\left(\mathrm{R}^{2}\right)$ represent variance explained and the consistency of the model to predict the dependent variables (see Figure 1).

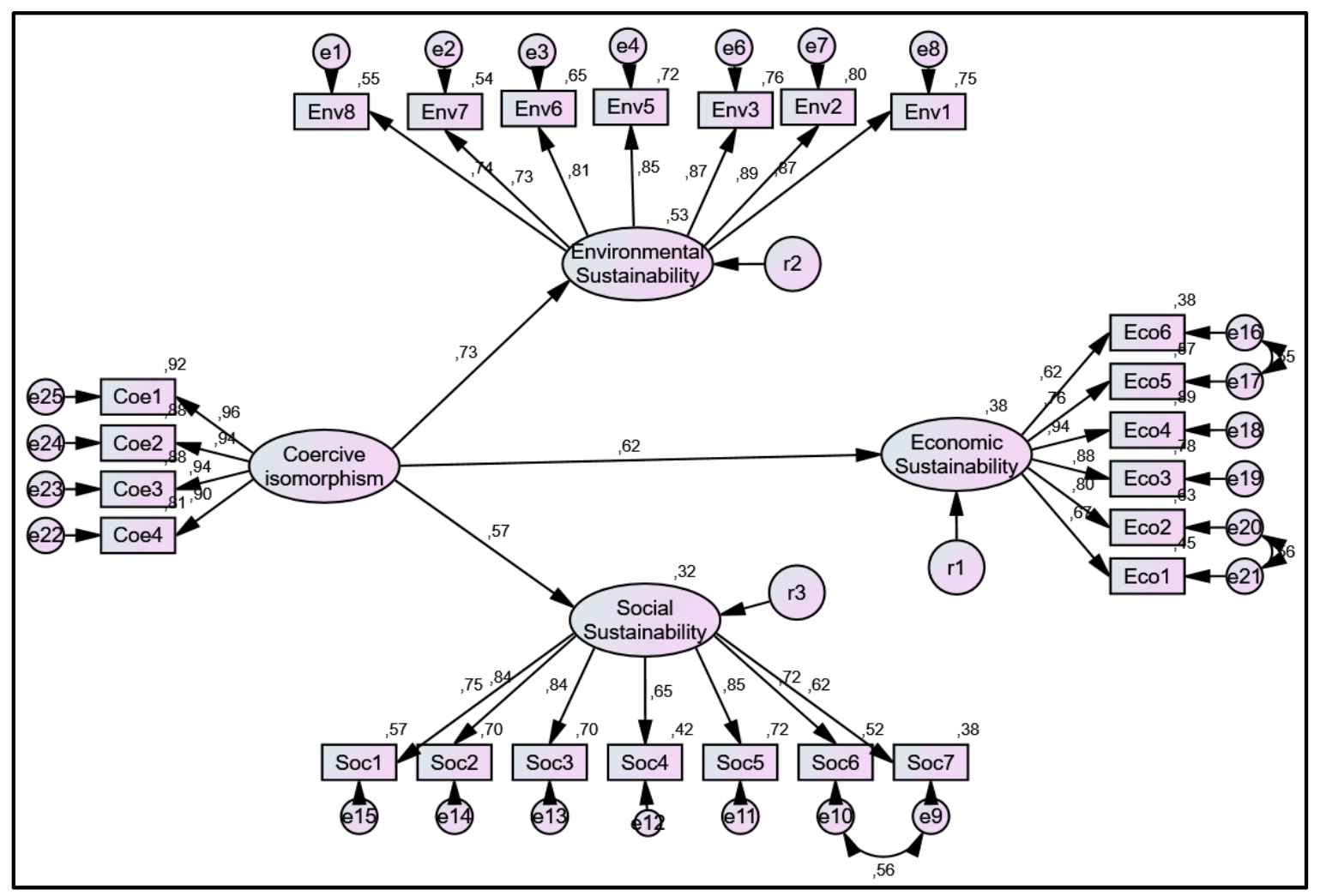

Figure 1. Structural Model Results.

The $\mathrm{R}^{2}$ values for economic, environmental and social sustainability of $0.37,0.57$ and 0.39 respectively, reviewed satisfactory predictive ability of the model. The results of SEM analysis showed the Goodness-of-Fit (GOF) indices reflected moderate fit of the model to the data, regardless of the chi-square being significant (chi-square $=665.676, \mathrm{df}=246, p=0.000, \mathrm{~N}=222$ ). As indicated in literature, the chi-square is subjective to large sample sizes of above 200 [49]. The other fit indices indicated acceptable model fitness, thus, $\mathrm{GFI}=0.846, \mathrm{NFI}=0.927, \mathrm{CFI}=0.939, \mathrm{TLI}=0.908, \mathrm{AGFI}=0.787$, $\mathrm{RMR}=0.067, \mathrm{RMSEA}=0.097, \mathrm{SRMR}=0.0602, \mathrm{PNFI}=0.719, \mathrm{AIC}=2247.023$, Chi-square $/ \mathrm{df}=2.706$. Table 4 below indicates that all the three hypotheses formulated in the study were found to be positive and significant in the structural model presented in Figure 1 above.

Using the standardised regression weights, coercive isomorphism was found to strongly and positively influence economic $(\beta=0.62, p<0.001)$, environmental $(\beta=0.73, p<0.001)$ and social ( $\beta=0.57, p<0.001)$ sustainable development practices. As such, all the three hypotheses that were postulated in this study were supported by the data through SEM analysis. Thus, at the alpha significant level 0.05 , all the null hypotheses pertaining to the study were rejected. 
Table 4. SEM Hypotheses Testing Results.

\begin{tabular}{cccccccc}
\hline \multicolumn{2}{c}{ Hypothesised Relationship } & $\beta$ & S.E. & C.R. & $p$ & Rejected or Supported \\
\hline Economic & $<-$ & Coercive & 0.619 & 0.042 & 7.679 & $* * *$ & Supported \\
Environmental & $<-$ & Coercive & 0.725 & 0.056 & 10.269 & $* * *$ & Supported \\
Social & $<-$ & Coercive & 0.569 & 0.041 & 7.054 & $* * *$ & Supported \\
\hline
\end{tabular}

$\beta$, standardised regression weight; S.E., standard error; C.R., critical ratio; $p$, probability value; ${ }^{* * *}$, Denotes $p<0.001$.

\subsection{Discussion of Results}

This study reveals that coercive forces such as government pressures and other regulatory bodies have an impact on SMEs embarking on economic, environmental and social sustainability practices. Thus, from the SEM results, there is strong evidence that SMEs owner/managers are of the perception that coercive pressures underpin participation in sustainable development practices. More specifically, the high path regression weight on coercive sustainable development and economic sustainability of 0.619 indicates that the more coercive pressure that is imposed on SMEs the more they will adopt practices that are economically sustainable. The same can be inferred in regards to the relationship between coercive pressures and environmental practices with a path regression weight of 0.725 . Furthermore, the influence of coercive forces was found to be strong and positive with regard to social sustainability practices by SMEs as posited by the path regression weight of 0.569 .

The study established that coercive forces are more influential in the adoption of economic and environmental sustainability practices by SMEs as compared to social sustainability practices. The implications are that the more government rules and regulations, customer as well as supplier pressures are critical to the adoption of sustainable practices. Literature that is directly related to coercive isomorphism and sustainable development practices is scarce. As such, findings of this study are examined in light of findings in other studies that pertain to the variables hypothesised, herein. The results of this study are consistent with the findings of Bondy [58] who found that coercive isomorphic pressures such as government and regulatory bodies were very significant in determining behaviours that are sustainable. Bondy's [58] study focused on multinational companies in the United Kingdom and utilised a qualitative research approach.

The role of coercive isomorphic pressures towards sustainable development behaviours was established in studies conducted in Malaysia [48]. Although the study related to municipalities, it established that there was a significant and positive relationship between coercive isomorphism and an example of environmental sustainability practices, namely, environmental sustainable disclosure. Also, specifically, the results of the current study are consistent with the findings of past studies which established that coercive pressures positively affected environmental management practices [7,31].

\section{Conclusions}

To date, the literature that exists, especially on sustainable development practices, has not been structured and properly defined. In this regard, the study contributes significantly by structuring literature as well as contributing towards the scarce works on the operationalisation of the three dimensions of sustainable development, namely, economic, environmental and social. The evaluation of literature has indicated that the environmental and social dimensions have been operationalised to a greater extent compared to the economic dimension within the sustainable development context. Furthermore, regarding the multidimensionality of the concept of sustainable development, the study contributes towards understanding the different relationships amongst these concepts and provided a holistic approach towards sustainable development. Whereas, latent research has broadly considered these concepts separately, the study contributes towards the management of sustainable development. Foremost, the literature in this study provides a better classification of practices in the sustainability context. The study will enhance the understanding of SME/managers as far as the three dimensions of sustainability are concerned. Apparently, it is becoming increasingly demanding for managers of both 
large and small businesses to be conversant of corporate sustainability practices. As such, this study will contribute towards the managerial competency, particularly, SMEs within the sustainable development context.

Furthermore, government needs to observe the role that institutional forces play towards sustainable development adoption, especially coercive and normative. As observed in the study, there was a significant relationship between coercive isomorphism and the three dimensions of sustainable development. This means that for sustainable development practices to increase amongst SMEs, policies, laws and regulations are instrumental. There is need for government to be explicit at every government level, from national to local. Sustainability is a paramount aspect that cannot be treated with an ad hoc approach, but rather, through more formalised programmes and even a ministry on sustainable development is needed, since sustainability is a long-lasting phenomenon. Furthermore, the coercive forces emanating from institutional forces such as customers, suppliers, society and rivalries in the market environment are worthy consideration. In the absence of laws, policies and regulations these stated coercive forces should be expected to accelerate the adoption of sustainability practices amongst SMEs. Considering, the fragility of small businesses and how extraneous government and legal regulations have been frowned upon, the role of these non-regulatory coercive forces becomes very essential. As such, the South African government needs to involve all business players within the supply chain in initiatives that ensure that all businesses occupy an active role in encouraging sustainability practices within their respective industries. This also calls for sustainable education to be enhanced amongst firms which will potentially result in all businesses increasing coercive pressures and demands over their counterparts and somehow play the watchdog role on behalf of the government. The major limitation pertained to literature constraint in the face of the SEM analytical approach. Theory and literature are vital aspects of the structural equation modelling approach. In this case, the available literature was not adequate for the study of this magnitude. Literature on sustainable development and isomorphism was found to be very limited. Also, empirical studies in these areas are very scarce. Furthermore, the research was only conducted in Limpopo province. As such, the findings of this study seldom represent the South African context. Thus, for proper representation the study can be conducted on a national scale.

For the future, research is needed to identify how the different typologies of SMEs are placed on the praxis of the proposed theory in the study. The present study took an aggregated approach to the analysis of SMEs pertaining to the concepts of coercive isomorphism and sustainable development. Future studies can investigate the same concepts based on the differences found in the SMEs. Such differences could be geographic (regions, country, globally), size, duration as well as industrial segments. Also, major theoretical contributions can be made if research can be done to identify the role of incentives and rewards in sustainability whistleblowing amongst firms. Thus, there is a significant need to research to what extent coercive pressures amongst small businesses can be enhanced through such strategies, and we postulate that rewards and incentives have the potential to enhance compliance and adoption amongst SMEs.

Author Contributions: R.M. was responsible for the compilation, analysis and write-up of the entire study. O.F. supervised the study and contributed through editing.

Funding: No external funding was received for the purposes of carrying out this study.

Conflicts of Interest: The authors declare no conflict interest. 


\section{Appendix A}

Table A1. Items used to measure coercive isomorphism and sustainability practices.

\begin{tabular}{|c|c|}
\hline Item & Code \\
\hline \multicolumn{2}{|l|}{ Coercive isomorphism } \\
\hline $\begin{array}{l}\text { Our main customers that matter to us believe that we should use sustainable business practices. } \\
\text { We may not retain our important customers without sustainable business practices. } \\
\text { Our suppliers that matter to us believe that we should use sustainable business practices. } \\
\text { There are rules and regulations that enforce us to use sustainable business practices. }\end{array}$ & $\begin{array}{l}\text { Coe1 } \\
\text { Coe2 } \\
\text { Coe3 } \\
\text { Coe4 }\end{array}$ \\
\hline \multicolumn{2}{|l|}{ Environmental sustainability } \\
\hline $\begin{array}{l}\text { Our sustainable business practices focus on environmental issues. } \\
\text { Our sustainable business practices make the most efficient use of the resources available in } \\
\text { the environment. } \\
\text { Our sustainable business practices recycle, reuse and reduce waste. } \\
\text { Our sustainable business practices are based upon environmental monitoring. } \\
\text { Our sustainable business practices are increasing energy efficiency. } \\
\text { Our sustainable business practices emphasise on use of renewable energy. } \\
\text { Our sustainable business practices make use of reduction/replacement of hazardous chemicals or } \\
\text { materials (e.g., substituting hazardous chemicals with less hazardous alternatives). } \\
\text { Our sustainable business practices adhere to Environmental Protection Agency regulations } \\
\text { on effluents/emissions/waste. }\end{array}$ & $\begin{array}{l}\text { Env1 } \\
\text { Env2 } \\
\text { Env3 } \\
\text { Env4 } \\
\text { Env5 } \\
\text { Env6 } \\
\text { Env7 }\end{array}$ \\
\hline \multicolumn{2}{|l|}{ Economic sustainability } \\
\hline $\begin{array}{l}\text { Our sustainable development practices rest on economic considerations such as efficiency and } \\
\text { productivity. } \\
\text { Our sustainable development practices focus on survival in the marketplace. } \\
\text { Our sustainable development practices save money for the firm. } \\
\text { Our sustainable development practices meet tax obligations. } \\
\text { Our sustainable development practices provide products and services that are important for } \\
\text { the community. } \\
\text { Our sustainable development practices focus on long-term profitability even if it means losses in } \\
\text { the short-term. }\end{array}$ & $\begin{array}{l}\text { Eco1 } \\
\text { Eco2 } \\
\text { Eco3 } \\
\text { Eco4 } \\
\text { Eco5 }\end{array}$ \\
\hline \multicolumn{2}{|l|}{ Social sustainability } \\
\hline $\begin{array}{l}\text { Our sustainable development practices take current activities in the community into account. } \\
\text { Our sustainable development practices consider the social well-being of society. } \\
\text { Our sustainable business practices provide entitlements to workers. } \\
\text { Our sustainable business practices promote women to senior management positions. } \\
\text { Our sustainable business practices focus on equity and safety of the community. } \\
\text { Our sustainable business practices focus on improving the general education level. } \\
\text { Our sustainable business practices promote individual rights both civil and human rights. }\end{array}$ & $\begin{array}{l}\text { Soc1 } \\
\text { Soc2 } \\
\text { Soc3 } \\
\text { Soc4 } \\
\text { Soc5 } \\
\text { Soc6 } \\
\text { Soc7 }\end{array}$ \\
\hline
\end{tabular}

\section{References}

1. Masocha, R.; Fatoki, O. The role of mimicry isomorphism in sustainable development operationalization by SMEs in South Africa. Sustainability 2018, 10, 1264. [CrossRef]

2. Rishi, M.; Jauhari, V.; Joshi, G. Marketing sustainability in the luxury lodging industry: A thematic analysis of preferences amongst the Indian transition generation. J. Consum. Mark. 2015, 32, 376-391. [CrossRef]

3. Borim-de-Souza, R.; Balbinot, Z.; Travis, E.F.; Munck, L.; Takahashi, A.R.W. Sustainable development and sustainability as study objects for comparative management theory. Cross Cult. Manag. 2015, 22, $201-235$. [CrossRef]

4. Swanson, L.A.; Zhang, D.D. Perspectives on corporate responsibility and sustainable development. Manag. Environ. Qual. Int. J. 2012, 23, 630-639. [CrossRef]

5. Ratiu, C.; Anderson, B.B. The identity crisis of sustainable development. World J. Sci. Technol. Sustain. Dev. 2014, 11, 4-15. [CrossRef] 
6. Høgevold, N.M.; Svensson, G.; Klopper, H.B.; Wagner, B.; Valera, J.C.S.; Padin, C.; Ferro, C.; Petzer, D. A triple bottom line construct and reasons for implementing sustainable business practices in companies and their business networks. Corp. Gov. 2015, 15, 427-443. [CrossRef]

7. Jamil, C.Z.M.; Mohamed, A.A.; Muhammad, F.; Ali, A. Environmental management accounting practices in small medium manufacturing firms. Procedia Soc. Behav. Sci. 2015, 172, 619-626. [CrossRef]

8. Chow, W.S.; Chen, Y. Corporate Sustainable Development: Testing a New Scale Based on the Mainland Chinese Context. J. Bus. Ethics 2012, 105, 519-533. [CrossRef]

9. Wang, Y. What are the biggest obstacles to growth of SMEs in developing countries? An empirical evidence from an enterprise survey. Borsa Istanb. Rev. 2016, 16, 167-176. [CrossRef]

10. Iederan, O.C.; Curçeu, P.L.; Vermeulen, P.A.M.; Geurts, J.L.A. Antecedents of Strategic Orientations in Romanian SMEs: An Institutional Framing Perspective. J. East Eur. Manag. Stud. 2013, 18, 386-408. [CrossRef]

11. Maduku, D.K.; Mpinganjira, M.; Duha, H. Understanding mobile marketing adoption intention by South African SMEs: A multi-perspective framework. Int. J. Inf. Manag. 2016, 36, 711-723. [CrossRef]

12. Cambra-Fierro, J.; Hart, S.; Polo-Redondo, Y. Environmental Respect: Ethics or Simply Business? A Study in the Small and Medium Enterprise (SME) Context. J. Bus. Ethics 2008, 82, 645-656. [CrossRef]

13. Cheng, H.; Yu, C.J. Adoption of Practices by Subsidiaries and Institutional Interaction within Internationalised Small-and Medium-Sized Enterprises. Manag. Int. Rev. 2012, 52, 81-105. [CrossRef]

14. Windolph, S.E.; Schaltegger, S.; Herzig, C. Implementing corporate sustainability: What drives the application of sustainability management tools in Germany. Sustain. Account. Manag. Policy J. 2014, 5, 378-404. [CrossRef]

15. Venkatraman, S.; Nayak, R.R. Corporate sustainability: An IS approach for integrating triple bottom line elements. Soc. Responsib. J. 2015, 11, 482-501. [CrossRef]

16. Martínez-Ferrero, J.; García-Sánchez, I. Coercive, normative and mimetic isomorphism as determinants of the voluntary assurance of sustainability reports. Int. Bus. Rev. 2017, 26, 102-118. [CrossRef]

17. Sutheewasinnon, P.; Hoque, Z.; Nyamori, R.O. Development of a performance management system in the Thailand public sector: Isomorphism and the role and strategies of institutional entrepreneurs. Crit. Perspect. Account. 2016, 40, 26-44. [CrossRef]

18. Lai, K.; Wong, C.W.Y.; Cheng, E. Institutional isomorphism and the adoption of information technology for supply chain management. Comput. Ind. 2006, 57, 93-98. [CrossRef]

19. Lin, R.; Sheu, C. Why do Firms Adopt/Implement Green Practices-An Institutional Theory Perspective. Procedia Soc. Behav. Sci. 2012, 57, 533-540. [CrossRef]

20. Urban, B.; Naidoo, R. Business sustainability: Empirical evidence on operational skills in SMEs in South Africa. J. Small Bus. Enterp. Dev. 2012, 19, 146-163. [CrossRef]

21. Deniz, D. Improving sustainability concept in developing countries: Sustainable thinking and environmental awareness through design education. Procedia Environ. Sci. 2016, 34, 70-79. [CrossRef]

22. Issahaku, A.; Ganiyu, A.A.; Sophia, A. Reducing the Rate of Poverty in Tamale Metropolis: The Role of Small and Medium Enterprises. Int. J. Econ. Commer. Manag. UK 2015, 3, 1-18.

23. Moreira, D.F. The microeconomic impact on growth of SMEs when the access to finance widens: Evidence from internet \& high-tech industry. Procedia Soc. Behav. Sci. 2016, 220, 278-287. [CrossRef]

24. Eze, U.C.; Goh, G.G.G.; Goh, C.Y.; Tan, T.T. Perspectives of SMEs on knowledge sharing. VINE 2013, 43, 210-236. [CrossRef]

25. Asamoah, E.S. Customer based brand equity (CBBE) and the competitive performance of SMEs in Ghana. J. Small Bus. Enterp. Dev. 2014, 21, 117-131. [CrossRef]

26. Di Maggio, P.J.; Powell, W.W. The Iron Cage Revisited: Institutional Isomorphism and Collective Rationality in Organisational Fields. Am. Soc. Rev. 1983, 48, 147-160. [CrossRef]

27. Buchko, A. Institutionalization, Coercive Isomorphism, and the Homogeneity of Strategy. Adv. Bus. Res. 2011, 2, 27-45.

28. Wu, T.; Daniel, E.M.; Hinton, M.; Quintas, P. Isomorphic mechanisms in manufacturing supply chains: A comparison of indigenous Chinese firms and foreign-owned MNCs. Supply Chain Manag. Int. J. 2013, 18, 161-177. [CrossRef]

29. Chiang, C. Insights into current practices in auditing environmental matters. Manag. Audit. J. 2010, 25, 912-933. [CrossRef] 
30. Kauppi, K. Extending the use of institutional theory in operations and supply chain management research. Int. J. Oper. Prod. Manag. 2013, 33, 1318-1345. [CrossRef]

31. Kshetri, N. The development of market orientation: A consideration of institutional influence in China. Asia Pac. J. Mark. Logist. 2009, 2, 19-40. [CrossRef]

32. Yang, M.; Hyland, M. Re-examining mimetic isomorphism. Manag. Decis. 2012, 50, 1076-1095. [CrossRef]

33. González, J.M.G. Determinants of socially responsible corporate behaviours in the Spanish electricity sector. Soc. Responsib. J. 2010, 6, 386-403. [CrossRef]

34. Othman, S.; Darus, F.; Arshad, R. The influence of coercive isomorphism on corporate social responsibility reporting and reputation. Soc. Responsib. J. 2011, 7, 119-135. [CrossRef]

35. Giblin, M.J.; Burruss, G.W. Developing a measurement model of institutional processes in policing. Polic. Int. J. Police Strateg. Manag. 2009, 32, 351-376. [CrossRef]

36. Thiel, M. Unlocking the social domain in sustainable development. World J. Sci. Technol. Sustain. Dev. 2015, 12, 183-193. [CrossRef]

37. Galpin, T.; Whittington, J.L.; Bell, G. Is your sustainability strategy sustainable? Creating a culture of sustainability. Corp. Gov. 2015, 15, 1-17. [CrossRef]

38. Jamali, D.; Mirshak, R. Corporate Social Responsibility (CSR): Theory and Practice in a Developing Country Context. J. Bus. Ethics 2007, 72, 243-262. [CrossRef]

39. Jämsä, P.; Tähtinen, J.; Ryan, A.; Pallari, M. Sustainable SMEs network utilization: The case of food enterprises. J. Small Bus. Enterp. Dev. 2011, 18, 141-156. [CrossRef]

40. Marques, F.; Mendonça, P.S.M.; Jabbour, C.J.C. Social dimension of sustainability in retail: Case studies of small and medium Brazilian supermarkets. Soc. Responsib. J. 2010, 6, 237-251. [CrossRef]

41. Wilson, J.P. The triple bottom line. Int. J. Retail Distrib. Manag. 2015, 43, 432-447. [CrossRef]

42. Adebanjo, D.; Teh, P.; Ahmed, P.K. The impact of external pressure and sustainable management practices on manufacturing performance and environmental outcomes. Int. J. Oper. Prod. Manag. 2016, 36, 995-1013. [CrossRef]

43. Zhu, Q.; Sarkis, J. The moderating effects of institutional pressures on emergent green supply chain practices and performance. Int. J. Prod. Res. 2007, 45, 4333-4355. [CrossRef]

44. Hsu, C.; Tan, K.C.; Zailani, S.H.M.; Jayaraman, V. Supply chain drivers that foster the development of green initiatives in an emerging economy. Int. J. Oper. Prod. Manag. 2013, 33, 656-688. [CrossRef]

45. Diabat, A.; Govindan, K. An analysis of the drivers affecting the implementation of green supply chain management. Resour. Conserv. Recycl. 2011, 55, 659-667. [CrossRef]

46. Van Zeijl-Rozema, A.; Cörvers, R.; Kemp, R.; Martens, P. Governance for Sustainable Development: A Framework. Sustain. Dev. 2008, 16, 410-421. [CrossRef]

47. Martinez-Conesa, I.; Soto-Acosta, P.; Palacios-Manzano, M. Corporate social responsibility and its effect on innovation and firm performance: An empirical research in SMEs. J. Clean. Prod. 2017, 142, 2374-2383. [CrossRef]

48. Joseph, C.; Taplin, R. Local government website sustainability reporting: A mimicry perspective. Soc. Responsib. J. 2012, 8, 363-372. [CrossRef]

49. Ortas, E.; Alvarez, I.; Jaussaud, J.; Garayar, A. The impact of institutional and social context on corporate environmental, social and governance performance of companies committed to voluntary corporate social responsibility initiatives. J. Clean. Prod. 2015, 108, 673-684. [CrossRef]

50. Bryman, A.; Bell, E. Research Methodology: Business and Management Contexts; Oxford University Press: Cape Town, South Africa, 2011.

51. Hoyle, R.H. Structural Equation Modeling for Social and Personality Psychology; Sage Publications Inc.: London, UK, 2011; ISBN 978-0-85702-405-3.

52. Rajeh, M.; Tookey, J.E.; Rotimi, J.O.B. Estimating transaction costs in the New Zealand construction procurement: A structural equation modelling methodology. Eng. Constr. Arch. Manag. 2015, 22, 242-267. [CrossRef]

53. Siddiqui, K.A.; Mirani, M.A.; Fahim, S.M. Model generation using structural equation modelling. J. Sci. Res. Dev. 2015, 2, 112-116.

54. Mishra, P. Business Research Methods; Oxford University Press: New Dehli, India, 2015. 
55. Brown, T.A.; Moore, M.T. Confirmatory Factor Analysis. 2013. Available online: https: //www.researchgate.net/profile/Michael_Moore8/publication/251573889_Hoyle_CFA_Chapter_-_ Final/links/Odeec51f14d2070566000000/Hoyle-CFA-Chapter-Final.pdf (accessed on 28 July 2017).

56. De Carvalho, J.; Chima, F.O. Applications of Structural Equation Modeling in Social Sciences Research. Am. Int. J. Contemp. Res. 2014, 4, 6-11.

57. Bryne, B.M. Structural Equation Modelling with Amos-Basic Concepts, Applications and Programming, 2nd ed.; Taylor and Francis Group, LLC.: New York, NY, USA, 2009; ISBN 9780805863727.

58. Bondy, K. Isomorphism in the Practice of Corporate Social Responsibility: Evidence of an Institution and Its Decline; University of Bath School of Management: Bath, UK, 2009; Available online: http://www.bath.ac.uk/ management/research/papers.htm (accessed on 5 September 2017).

2018 by the authors. Licensee MDPI, Basel, Switzerland. This article is an open access article distributed under the terms and conditions of the Creative Commons Attribution (CC BY) license (http:/ / creativecommons.org/licenses/by/4.0/). 